\section{Educação ambiental: abordagem no ensino superior de Geografia}

Resumo: Muito se fala nos temas referentes à questão ambiental. ONGs, conferências a nível mundial, mudança na legislação, enfim, observa-se a inserção dos temas em diversas esferas sociais, especialmente na educação em seus diversos níveis. Com o objetivo de elucidar a importância dos princípios da Educação Ambiental na prática de ensino da Geografia, entende-se que é relevante abordar os pressupostos do Pensamento Ecológico, do Ecologismo e da Educação Ambiental. Então, foi levantada uma investigação de como se dá a aplicação do discurso ecológico dos professores de Geografia numa universidade, da qual a selecionada foi a UEL - Universidade Estadual de Londrina, e sobre a importância de incluí-lo na prática pedagógica.

\section{Environmental education: approach on the Geography teaching in higher education}

\begin{abstract}
A lot has being said about the themes related to the environmental issue. NGOs, world conferences, change in the Legislation, in brief, it is possible to observe the insertion of the theme in many social spheres, especially in the education in its different levels. With the aim of elucidating how important the Environmental Education principles are to the Geography teaching practice, it is relevant to raise the theory related to: the Ecological Thinking, Ecologism and the Environmental Education as well. In order to achieve that, it was done an investigation: on how the Geography teacher's ecological speech occurs in an University- Universidade Estadual de Londrina (UEL) - and about the importance of including it in the teaching practice.
\end{abstract}

\section{Cinthia Raquel Pergentino de Oliveira* José Edézio da Cunha**}

* Mestre em Geografia pela Unioeste, Campus de Francisco Beltrão-PR, Professora de Geografia da Rede Estadual de Ensino-PR.

** Unioeste, Campus de Marechal Cândido Rondon, Professor Adjunto de Geografia da Unioeste, Campus de Marechal Cândido Rondon

Palavras-chave: Pensamento ecológico; Ecologismo;

Educação ambiental; Ensino de Geografia.

Key-words: Ecological Thinking; Ecologism; Environmental

Education; Geography teaching 


\section{Introdução}

O meio ambiente insalubre compromete a qualidade de vida do homem como também o próprio ambiente físico. A sociedade deseja viver em um mundo melhor, mais pacífico, mais ecológico, com menos pobreza. No entanto, diante dos nossos ideais ambientais, não podemos esperar que as mudanças ocorram a partir do "sistema" (econômico), pois, a responsabilidade com o meio ambiente, também depende das nossas ações.

As décadas de 1960 e 1970 despontam como um marco de emergência sobre questionamentos e manifestações ecológicas, em nível mundial, embora as questões específicas e a expressão política sobre o tema tenham variado ao longo do tempo e do espaço.

$O$ tratamento da Educação Ambiental trabalhada neste artigo parte em situar que a questão ambiental se manifesta não só na degradação dos elementos da natureza, mas como um problema para a sociedade, vindo a interferir negativamente na sua qualidade de vida.

Vernier (1994) cita diversos meios de cidadãos ficarem mais atentos a respeito do seu meio ambiente mais saudável, como no caso da educação. Nem as leis, nem as taxas obrigarão os cidadãos a respeitar o meio ambiente se esse respeito espontâneo não lhes for inculcado pela educação.

A educação ambiental é pertinentemente um instrumento de difusão, de gestão, por sua capacidade de intervir no processo de construção social. No entanto, para que o conhecimento acerca dos problemas venha a ser disponibilizados e que se compreendam a fim de desenredar percepções na busca por melhores condições, as universidades, assim como todos os estabelecimentos de ensino superior, devem não somente advertir sobre problemas, mas também conceber soluções racionais.

Sobre a importância da difusão da preocupação ambiental no ensino, conforme Tristão (2004), em 1985 foi elaborada, na Colômbia, a "Carta de Bogotá", documento produzido no I Seminário sobre Universidade e Meio Ambiente para a América Latina, seminário que institui conceitos e critérios para a orientação de um plano de ação para a Educação Ambiental nas universidades latino-americanas e, concomitantemente, reflete sobre a limitação dessas instituições para sua efetivação. No documento se recomenda que as universidades realizem uma avaliação dos conteúdos e dos métodos dos programas existentes, a fim de facilitar a incorporação integrada da dimensão ambiental, evitando posições reducionistas.

A perspectiva deste trabalho visa compreender a incorporação da Educação Ambiental na Universidade Estadual de Londrina, PR, cujo objetivo procura contemplar se o envolvimento do discurso ecológico faz-se necessário ou se trata de um modismo. A discussão está fundamentada na idéia de Pensamento Ecológico e como a sua atuação por meio do Ecologismo está demonstrando seus valores e sua inserção na Geografia.

\section{Pensamento ecológico}

A ciência moderna, herdada de pensadores como Galileu, Bacon, Descartes, Newton e

Geografia Ensino \& Pesquisa, v. 16, n.1, p. 145154, jan.jjun. 2012

Educação ambiental: abordagem no ensino superior de Geografia outros seguidores, criou um instrumento teórico-metodológico de produção de conhecimento que fragmenta a realidade, decompondo-a em campos de estudo, cada campo representando partes de uma totalidade. "Há uma tendência ao isolacionismo dessas partes, até mesmo pelo aprofundamento extremo do conhecimento produzido, afastando-se da interligação entre as partes e a visão do todo" (GUIMARÃES, 1995, p. 88). 
Odum (1977) afirma que, com a chegada da Era Atômica, o assunto sobre ambientes tornou-se mais excitante, mais importante até do que o fora antes da Segunda Guerra Mundial, pois as promessas e as ameaças da energia atômica, conjugadas às da explosão da população humana, conduziram os problemas ambientais a um importante questionamento por parte da sociedade. Sendo assim, ainda conforme o autor, é necessário que cada jovem cientista, e mesmo cada pessoa educada, se familiarize pelo menos com os processos ambientais fundamentais e com as condições que tornam possível a simples sobrevivência, para não mencionar o prosperar, dos organismos individuais, tais como nós mesmos. Dando continuidade ao pensamento do autor, o mesmo cita que

Numa democracia não basta existirem apenas algumas poucas pessoas treinadas que saibam o que está acontecendo ao seu redor, devem existir, também, cidadãos alertas, que insistam em que o conhecimento, a pesquisa e a ação estejam adequadamente integrados. (ODUM, 1977, p. 19-20)

Sobre essa citação, a respeito de uma preocupação mais compromissada como o nosso ambiente, como também da falta dela, Capra (2006) faz uma reflexão acerca de um novo paradigma. Este novo paradigma se volta para mudanças nas percepções e nas maneiras de pensar os aspectos essenciais de todos os sistemas vivos - o Pensamento Ecológico.

$\mathrm{O}$ autor cita que, quanto mais estudamos os principais problemas de nossa época, mais somos levados a perceber que eles não podem ser entendidos isoladamente. Os problemas são sistêmicos, o que significa que estão interligados e são interdependentes. Como exemplo, temos a escassez dos recursos e a degradação do meio ambiente, que se combinam com populações em rápida expansão, o que leva ao colapso das comunidades locais e à violência étnica e tribal, que se tornou a característica mais importante da era pós-guerra fria.

Assim, esses problemas precisam ser vistos como diferentes facetas de uma única crise a chamada crise de percepção.

Ela deriva do fato de que a maioria de nós, e em especial nossas grandes instituições sociais, concordam com os conceitos de uma visão de mundo obsoleta, uma percepção da realidade inadequada para lidarmos com nosso mundo superpovoado e globalmente interligado. (CAPRA, 2006, p. 23)

Para que haja soluções dos principais problemas (como os ambientais, os sociais e os econômicos), é necessário haver uma mudança radical em nossas percepções, no nosso pensamento e nos nossos valores.

Porém, essa compreensão ainda não despontou entre a maioria dos nossos líderes políticos. 0 reconhecimento de que é necessária uma profunda mudança de percepção e de pensamento para garantir a nossa sobrevivência ainda não atingiu a maioria dos nossos líderes das nossas corporações, nem os administradores e os professores das nossas grandes universidades. (CAPRA, 2006, p. 23-24)

Tozoni-Reis (2004), corroborando o mesmo sentido da visão de Capra, (2006), salienta a necessidade de uma nova ordem que possibilite uma nova forma de os seres humanos se relacionarem com a natureza. Corresponde, assim, a adoção de uma nova ética, em que se destaque como prioridade a dimensão coletiva (no sentido de abarcar toda a humanidade) e a dimensão democrática (no sentido de incluir a igualdade, mesmo na diversidade) nas relações

Geografia Ensino \& Pesquisa, v. 16, n.1, p. 145154, jan.jun. 2012

Oliveira, C. R. P.; Cunha, J. E.

ISSN 2236- 4994 
entre pessoas e grupos. Essa nova ordem articula a perspectiva ecológica e a perspectiva democrática, sendo expressa na citação de Souza (1992 apud TOZONI-REIS, 2004, p. 61):

\begin{abstract}
O pensamento ecológico pode constituir-se num ponto de partida capaz de aprofundar a crítica do desenvolvimento, tal como realizado no mundo moderno, e de unir e produzir uma nova confluência cultural e ideológica, que se move em direção à democracia, onde não somente os homens e mulheres possam se encontrar num mundo de todos, como também estabelecer uma relação de qualidade diferente com a natureza de que somos parte e pela qual somos responsáveis. Os princípios básicos das relações humanas já foram propostos, não estabelecidos, pelo pensamento democrático. Os princípios básicos das relações entre humanidade e a natureza ainda não foram devidamente discutidos e estabelecidos entre nós, o que nos leva muitas vezes a produzir dicotomias inconsistentes e falsas contradições. Este é um desafio moderno. Não fomos capazes de incluir em nosso horizonte toda a humanidade, nem fomos capazes de nos incluir no horizonte de um universo que nos ultrapassa em tantas dimensões. Ao recuperarmos um desafio de tal magnitude, talvez sejamos capazes de recuperar também a capacidade de nos superarmos.
\end{abstract}

De acordo com o dicionário de Filosofia de Durozoi (1993), pensamento vem a ser:

No sentindo mais amplo, o pensamento abrange todos os fenômenos do espírito. Descartes emprega a palavra nessa acepção, mesmo que subtenda que a alma conhece simultaneamente os fenômenos em questão. Por oposição aos sentimentos e volições, o pensamento é então sinônimo de inteligência. No sentido mais estrito, designa o entendimento e a razão como capacidades de compreender a matéria do conhecimento e de fazer uma síntese mais elevada do que a percepção, a memória ou a imaginação. (DUROZOI, 1993, p. 359)

${ }^{1}$ Ideias fixas

Geografia Ensino \& Pesquisa, v. 16, n.1, p. 145154, jan.j.jun. 2012

Educação ambiental: abordagem no ensino superior de Geografia

148

ISSN 2236-4994
No Dicionário Escolar da Língua Portuguesa (1985, p. 647) constata-se que o pensamento é "Ato ou efeito de pensar; processo mental humano que permite refletir, julgar, realizar abstrações, análise e síntese. Em sentido lato, o termo se refere ao conjunto de fatos psíquicos; fantasia; idéia; mente; espírito".

Assim, portanto, por pensamento entende-se 0 ato ou 0 efeito associado à compreensão e ao conhecimento das ações. Se a pensamento associarmos o adjetivo "ecológico", sendo este derivado da Ecologia, que é o "[...] estudo da estrutura e função da Natureza" (ODUM, 1977, p. 22) - estudo que considera a humanidade como parte da natureza, então se constitui o Pensamento Ecológico numa forma holística e integrada de pensar o mundo, a natureza e o meio ambiente.

Segundo Vincent (1995), o autor cita que há alguns esboços no acervo ecológico que muitos preferem ignorar ou contornar, pois dizem respeito às origens mais antigas das preocupações ecológicas. $\mathrm{O}$ autor destaca, em sua obra, três momentos concernentes e distintos acerca do Pensamento Ecológico. 0 primeiro enfoque é o mais comum à maioria das ideologias. Refere-se à tentativa de remontar os sentimentos ecológicos aos primórdios da espécie humana, pelo menos no Paleolítico e no Neolítico. Ainda, segundo o autor, diversos grupos, como os celtas ou os povos tribais, por exemplo, tornaram-se idées fixes ${ }^{1}$ dos autores ecológicos, consistindo em que essas gentes eram, ou são, mais "naturalmente" ou ecologicamente conscientes do que nós. Demonstravam uma percepção mais cuidadosa do mundo à sua volta, dando a impressão de que respeitavam implicitamente a natureza e dela só extraíam o de que precisavam. Assim, atribuía-se aos povos primitivos uma espécie de sabedoria natural e ancestral, sabedoria que nos seria importante redescobrir. 
O mesmo autor destaca que esse pensamento é vago e que tal afirmação condiz com o que existe atualmente, ou seja, o perigo de buscarmos com um ardor impróprio esses sentimentos que queremos encontrar nos povos primitivos, transferindo suas mitologias e crenças para nossas ansiedades sociais e ambientais. Assim ignoramos, em nosso prejuízo, o fato de a mentalidade do 'golpear e queimar' e a poluição e a destruição do habitat serem tão característicos dos seres humanos neolíticos quanto dos que hoje destroem a floresta tropical brasileira. Essas práticas são, de início, frequentemente associadas à economia de subsistência. A paisagem da Europa não foi moldada simplesmente pela industrialização. Nas eras primitivas os homens eram limitados pelo número de habitantes, pela tecnologia e pelo meio ambiente social e econômico. "Entretanto, se determinados homens neolíticos inventassem uma serradeira de pedra, sem dúvida a utilizariam livremente" (VINCENTE, 1995, p. 211).

A segunda abordagem da origem do Pensamento Ecológico, sendo esta a mais popular e utilizada, data o movimento ecológico dos anos 1960 e 1970, pois muitos percebem o começo do processo de conscientização ecológica nos anos 1960. Vincent (1995) cita que vários autores enfocaram os textos que exerceram grande influência nessa época. Alguns dos primeiros foram "Silent Spring"2 (1962), de Rachel Carson; "The Population Bomb"3 (1968), de Paul Ehrlich, e "Tragedy of the Commons"4 (1968), de Garret Hardim.

Dando continuidade às acepções de Vincent, o terceiro enfoque está associado à reação do movimento romântico ao iluminismo no início do século XIX, ou seja, o Ecologismo incorpora uma reação crítica ao movimento citado, visto que a visão romântica, arcadiana, idealizava a vida simples rural e criticava o utilitarismo da nova sociedade industrial que surgia (HERCULANO, 1992). Yi-fu Tuan (1980) salienta que, no mundo ocidental, o sentimento pela natureza culminou com o movimento romântico dos séculos XVIII e XIX. A saúde e o bem-estar físico aparecem de maneira proeminente numa percepção romântica da vida no campo, porém mais importante para o movimento foi a ideia de virtude.

Um ambiente físico e um meio de vida (a dos agricultores) assumiram implicações moralistas. A cidade simbolizava corrupção e completa esterilidade. Era o lugar onde os homens lutavam por poder e vaidade e, no entanto, sucumbiam às pequenas convenções sociais. 0 campo simbolizava a vida: a vida revelada nos frutos da terra, nas coisas verdes que crescem, na água pura e no ar limpo, na saudável família humana e na liberdade das coerções sociais e políticas arbitrárias (YI-FU TUAN, 1980, p. 273).

Para Vincent (1995) há, no entanto, controvérsias nesse pensamento. $O$ autor acredita que esta explicação apresenta um ponto fraco, pois o Pensamento Ecológico é céptico quanto ao valor da razão e também nega a posição central do homem e a ideia de que a natureza é passível de manipulação pelo homem. É crítica à ciência moderna. As crenças concernentes à igualdade global ou universal dos homens e das espécies, presentes em amplas áreas da ecologia, não se harmonizam com o caráter tradicionalista, localizado e, muitas vezes, hierarquicamente orientado do romantismo. Sendo assim, essa explicação não é concernente com o caráter tradicionalista embasado do romantismo.

Não se pode dizer, contudo, que o Pensamento Ecológico, como já citado, não é recente, embora Lago (1991) afirme que reflexões ecológicas que acionaram práticas inerentes pertencem a todas as épocas, pois aparecem entre os grupos do Paleolítico e do Neolítico. Complementando, o autor cita que, no entanto, o quadro de destruição de componentes da natureza, montado por povos paleolíticos e neolíticos, especialmente quanto à cobertura vegetal
2 "Primavera silenciosa", em que relatava sobre os pesticidas usados na agricultura sendo os responsáveis pelo desaparecimento de inúmeras espécies, como pássaros ameaçados de extinção. Esta obra criticava as conseqüências oriundas da tecnologia científica.

3 "A Bomba Populacional", obra na qual faz projeções catastróficas sobre as consequências da explosão demográfica, contra a corrente que sustenta ser a ciência moderna a salvadora de todos os nossos males - inclusive aqueles que têm como origem a superpopulação.

${ }^{5}$ Hardin construiu a metáfora da tragédia dos comuns como uma expressão da contradição entre racionalidade individual e racionalidade coletiva. 0 autor propõe, "[...] como alternativa à tragédia dos comuns, que os recursos apropriados coletivamente deveriam ser privatizados ou mantidos como propriedade do Estado que, por sua vez, definiria as regras de acesso e uso" (FEENY et al., 1990 apud CUNHA; COELHO, 2005 , p. 59). Conforme Cunha e Coelho (2005), Hardin apresenta uma grande preocupação com 0 crescimento populacional e, com isso, a tragédia dos comuns só será evitada quando cessar 0 crescimento populacional.

Geografia Ensino \& Pesquisa, v. 16, n.1, p. $145-$ 154, jan.jun. 2012

Oliveira, C. R. P.; Cunha, J. E.

ISSN 2236-4994 
e, por implicação, à fauna, nos revela razoável esforço de contenção de excessos de agressão. Como exemplo, cabe citar medidas de controle demográfico mediante esquemas culturais diversos, que representam inegáveis atestados de uma busca adaptativa em relação à capacidade limitada de provisões de recursos de ambientes. Sendo assim, 0 autor relata que 0 controle demográfico do período contribuiu para uma redução da agressão da natureza.

Consideramos fazer menção a uma abordagem do geógrafo Yi-fu Tuan (1980), da obra "Topofilia", quando o autor fala que, para compreender a preferência ambiental de uma pessoa, necessitaríamos examinar sua herança biológica, criação, educação, trabalho e os arredores físicos. Os temas abordados nessa obra - percepção, atitudes e valores - levam o leitor a compreender a si mesmo. 0 autor cita que, sem a autocompreensão, não podemos esperar por soluções duradouras para os problemas ambientais, que, por sua vez, são problemas humanos: "Todos os homens compartilham atitudes e perspectivas comuns, contudo a visão que cada pessoa tem do mundo é única e de nenhuma maneira é fútil" (YI-FU TUAN, 1980, p. 285).

Em sua obra "Espaço e Lugar", de 1983, Tuan explica que o espaço é, sem dúvida, mais do que um ponto de vista ou um sentimento complexo e fugaz. É uma condição para a sobrevivência biológica. Ocorre que a questão de quanto espaço um homem necessita para viver confortavelmente não tem um resposta simples, pois o espaço como recurso é uma apreciação cultural. O nível de aspiração afeta, sem dúvida, o que cada um considera como espaço adequado. Com isso, o autor mostra que cada um tem uma visão de mundo diferente. Aquilo (em relação a um lugar) que é sagrado para um, pode ser profano para outro.

Em função disso decorrem diferentes experiências com o meio ambiente - experiências de que podem surgir problemas ambientais em um determinado espaço, às vezes de modo não intencional. Assim, nesse contexto do advento do século XX, do qual se busca um registro holístico, que tem a globalização para partilhar cada vez mais os acontecimentos e realizar trocas de experiências, nota-se a disparidade de anseios por uma nova organização social e mudança no estilo de vida, com o intuito de superar a crise ecológica.

Muitas vezes, pode-se pensar que a Ecologia apresenta uma visão romântica, associandose mais em defesa do verde e, por extensão, da fauna e da flora. É preciso compreender que o ser humano é parte integrante da natureza, por isso não pode fazer o que bem entender. Apenas democratizar a informação acerca dos problemas ambientais não é suficiente sem uma articulação com uma educação - educação esta a ser concebida como Educação Ambiental, onde se aprende a pensar criticamente e a atuar de forma compromissada em seu meio ambiente.

\section{Ecologismo}

Conforme Branco (1997), diante da notoriedade dos fatos (degradação ambiental e percepção de que os recursos naturais são esgotáveis) surgiu, inicialmente em alguns setores mais intelectualizados da sociedade e, depois, em praticamente todos os demais, uma preocupação com a sobrevivência, com a segurança e com o destino do homem, tendo em vista

Geografia Ensino \& Pesquisa, v. 16, n.1, p. 145154, jan.j.jun. 2012

Educação ambiental: abordagem no ensino superior de Geografia a degradação dos ecossistemas dos quais ele inevitavelmente depende - o Ecologismo.

Este se trata de um movimento político-social e não de uma ciência.

Podemos perceber que os desequilibrios ecológicos são causados, conforme inúmeros estudos, em decorrência do modelo de desenvolvimento econômico vigente - o capitalismo. Há 
de se convir, no entanto, que os problemas ambientais também existem em países socialistas. É o caso dos grandes investimentos na construção da bomba atômica e das armas químicas, gerando instabilidade em qualquer forma de preservação e de conservação da natureza. Em outro exemplo, Lago (1991, p. 139) se refere à política socialista de Mao Tse-tung na década de 1960, em que "[...] o líder do mais populoso país do mundo falava arrogantemente que, se um conflito nuclear que envolvesse a China resultasse no extermínio de milhões de chineses, ainda sobrariam outras centenas de milhões".

O Ecologismo poderia ser entendido como uma ideologia política, por compreender explicações metafísicas da natureza da realidade, da natureza humana e do papel dos homens no mundo. Além disso, traz recomendações para uma vida social, econômica e politicamente melhor.

A influência do Ecologismo se revela em diversas instâncias da sociedade. Na política se manifesta através dos Partidos Verdes e na presença da questão ambiental nas agendas políticas. Na sociedade civil se manifesta através de movimentos ecológicos, como 0 Greenpeace International, a World Wildlife Fund (WWF), dentre outros.

Vincent (1995) indica que o Ecologismo vem da palavra "ecologia", utilizada pela primeira vez no fim da década de 1860 pelo zoólogo e filósofo alemão Ernst Haeckel. No caso, ecologia é uma palavra composta dos termos gregos oikos (que significa lar ou habitat) e logos (que significa argumentação ou ciência de alguma coisa). Nesse sentido, o significado da Ecologia revela uma relação primitiva e estreita com o termo "economia", que, em seu emprego original, segundo Aristóteles, significava administração do lar.

A Ecologia era, inicialmente, uma ciência que lidava com a relação sistemática entre as plantas e os animais e seu habitat ou ambiente. Embora conserve seu caráter de disciplina científica distinta, é de interesse não só dos biólogos, mas também de filósofos, de zoólogos, de matemáticos com tendências biológicas, de físicos, de geógrafos, de economistas e de urbanistas.

Vincent (1995) ainda cita uma estreita particularidade e referência do Ecologismo com a ecosfera, sendo esta concebida como um sistema inter-relacionado, merecendo nossa atenção para as responsabilidades globais e nossa inter-relação. $O$ autor complementa que o Ecologismo incorpora a influência científica e evolucionista, muitas vezes mesclada com um espiritualismo sutil, panteísta e holísta. Ernst Haeckel via a natureza como um organismo unificado, harmonioso, do qual os homens eram parte. Sendo assim, tinha muito a nos ensinar em termos de organização da sociedade, assim como de nossas relações com a natureza. Apesar de sua ampla promoção por vários grupos diferentes e politicamente diversos ao longo do século XX, foi a conjunção de circunstâncias e de manifestações no mundo ocidental, indivíduos e eventos na década de 1970, que propiciou um re-enfoque dinâmico do vocabulário ecológico.

\section{Metodologia}

Para a realização da pesquisa foram entrevistados professores de Geografia Física ${ }^{5}$ que ministram disciplinas de Educação Ambiental ou que apresentem esta particularidade de assunto, pois cabe averiguar a inserção da Educação ambiental como disciplina ou imbuída em diversas (disciplinas) na grade curricular. A escolha da universidade parte do critério em que o curso de licenciatura e bacharelado de Geografia implantado na instituição é um dos mais antigos das
${ }^{5}$ Não se trata de dicotomizar a ciência geográfica e destacar (afirmando) que a disciplina de Educação Ambiental seria trabalhada pelos professores da área Física, porque, diante da seleção dos professores ao averiguar seus currículos, coincidiram numa quantidade maior os professores de Geografia Física, embora a Educação Ambiental seja envolvida também na Geografia Humana.
Geografia Ensino \& Pesquisa, v. 16, n.1, p. 145-
154, jan.jjun. 2012
Oliveira, C. R. P.; Cunha, J. E.
ISSN 2236- 4994 
universidades localizadas no Estado do Paraná, sendo na UEL a licenciatura e o bacharelado criados em 1958. Dentre as perguntas aos sete professores destacam-se as seguintes:
a. É envolvido com atividades ambientalistas, associações sindicais e partidos políticos?
b. Que tipo de influência isso pode trazer ou não para a sua prática docente?
c. Tem uma prática docente relacionada à questão ambiental?

Para complementação das perguntas anteriores, sobre a importância de incluir a abordagem ambiental na prática pedagógica, interessa também saber de que forma os conhecimentos sobre a dimensão ambiental foram transmitidos a esses professores quando ainda eram graduandos:

d. Em que período foi sua graduação?

e. Qual curso?

f. Quando era graduando (a) teve Educação Ambiental ou alguma disciplina que atendesse esta particularidade de assunto?

g. Durante a sua graduação, havia na instituição que estudava eventos ou cursos de extensão e Pós-graduação que tratava do assunto?

h. Participava? Se sim ou não, por quê?

i. Acha importante que a Educação Ambiental deve ser uma nova disciplina curricular ou não. Por quê?

j. Procura unir teoria e prática em sua atividade pedagógica envolvendo a questão ambiental?

\section{Resultados}

Sobre a primeira pergunta quatro professores responderam que não são envolvidos e três responderam que sim; sobre a segunda pergunta, estes últimos otimizaram a relação da primeira questão com a segunda, e um citou: "Coloca em discussão uma série de conceitos que está na mídia, auxiliado assim, na prática docente". Referindo-se à importância de incluir a questão ambiental em sua prática docente, todos responderam que sim. As graduações dos professores entrevistados foram feitas em períodos variados, seja na década de 1960, 1970, 1980 e $1990 \mathrm{em}$ Geografia. Na pergunta seguinte sobre a inserção da Educação Ambiental ou de outra disciplina que conteria esta particularidade de assunto em sua graduação seis responderam que não havia, e uma professora que fizera seu curso em 1968 a 1972 respondeu que sim, intitulada "Estudos de problemas brasileiros". Se no período da sua graduação havia na própria instituição eventos ou cursos de extensão e Pós-graduação que tratava do assunto e se participavam e por que, quatro professores falaram que não e os demais falaram que sim. Sendo assim, os primeiros não participavam, porque não havia e os segundos participavam alegando interesse no assunto e uma professora salientou: "Porque a temática é envolvente". Outra questão se refere à Educação Ambiental devendo ser uma nova disciplina curricular ou não?" e continuando "Por quê?", sendo

Geografia Ensino \& Pesquisa, v. 16, n.1, p. 145154, jan.jjun. 2012

Educação ambiental: abordagem no ensino superior de Geografia assim, três professores responderam que sim, e uma professora justificou com a seguinte resposta: "Sim, no entanto, deveria perpassar por diversas disciplinas"; e os outros quatro professores que não concordam como sendo uma disciplina curricular apontaram: "Não, considerando que a disciplina "Educação Ambiental" não vai mudar a postura do indivíduo"; "Não, 
considerando um processo a ser imbuído no ensino médio e fundamental e envolvendo seus princípio em todas as disciplinas". E na última questão: "Procura unir teoria e prática em sua atividade pedagógica envolvendo a questão ambiental?" todos os professores mencionaram que sim.

\section{Considerações finais}

A importância do Pensamento Ecológico - sendo este interpretado numa forma holística, integrada de pensar o mundo, a natureza, o meio ambiente - na prática pedagógica deve-se, segundo a análise junto aos comentários dos professores, ao agravamento dos problemas ambientais, problemas que não só atingem a natureza como também o homem. Por isso, foi de grande relevância, nesta pesquisa, averiguar como a dimensão ambiental foi transmitida aos professores quando ainda eram graduandos. Devido a essa questão, onde a Geografia não pode deixar de incluir essa abordagem, é notória a importância dessa integração - ação humana e meio ambiente -, e, sendo assim, a percepção dos professores quanto a sempre envolver essa temática em conteúdos, metodologias, orientações.

Outra questão é compreender, entender o porquê dos sete professores selecionados inserirem a temática citada na prática pedagógica, sendo que os professores alegaram - em se tratando daqueles que não tiveram o conhecimento da Educação Ambiental quando graduandos - a falta que lhe fez 0 entendimento dessa questão. No tocante a esse propósito, observa-se a incorporação do Pensamento Ecológico no meio acadêmico, seja através das práticas docentes, seja, por sua vez, pela transcendência dessas práticas para a sociedade em geral e a sua integração nos programas universitários. Em síntese, as análises de como os professores de Geografia da universidade selecionada estão engajados nas suas práticas pedagógicas com a questão ambiental foi de extrema importância para demonstrar que a Educação Ambiental no meio acadêmico não se trata de um modismo, mas de uma necessidade de articular diferentes saberes sobre um meio ambiente complexo e do qual nós fazemos parte.

Baseando-se nas respostas dos professores, observa-se o esforço dos mesmos em envolver princípios da Educação Ambiental na disciplina, uma vez que esta perspectiva era oculta, não discutida na graduação de muitos deles. Sendo assim, percebemos nitidamente que a preocupação ecológica está bastante engajada nas atividades pedagógicas dos professores entrevistados, seja através de forma teórica como em atividades de campo, além de orientações de trabalhos acadêmicos.

A universidade tem um papel importante na formação ambiental de profissionais. Ela precisa incorporar a dimensão ambiental nos seus objetivos, conteúdos, metodologias.

Espera-se que os profissionais formados pela universidade, sejam capazes de atuar em diversas ações, principalmente educativas e civis de modo que essas ações sejam interativas e reflexivas, capazes de promover a participação dos diferentes agentes da sociedade.

\section{Referências bibliográficas}

ACADEMIA BRASILEIRA DE LETRAS. Dicionário escolar da língua portuguesa. São Paulo: Companhia Editora Nacional, 1995.

Geografia Ensino \& Pesquisa, v. 16, n.1, p. 145 154, jan.jjun. 2012

Oliveira, C. R. P.; Cunha, J. E. 
BRANCO, S. M. Ecologia e ecologismos. In: KUPSTAS, M. (org.). Ecologia em debate. 3.ed. São Paulo: Moderna, 1997

CAPRA, F.. A teia da vida: uma nova compreensão científica dos sistemas vivos. Trad. Newton Roberval Eichemberg. São Paulo: Cultrix, 2006.

CUNHA, L. H.; COELHO, M. C. N. Política e gestão ambiental. In: CUNHA, S. B. da; GUERRA, A. J. T. (org.). A questão ambiental: diferentes abordagens. 2.ed. Rio de Janeiro: Bertrand Brasil, 2005.

DUROZOI, G. Dicionário de filosofia. Campinas, SP: Papirus, 1993.

GUIMARÃES, Mauro. A dimensão ambiental na educação. Campinas. SP: Papirus, 1995.

HERCULANO, S.de C. Do desenvolvimento (in)suportável à sociedade feliz. In: GOLDENBERG, M. (coord.). Ecologia, ciência e política: participação social, interesse em jogo e luta de idéias no movimento ecológico. Rio de Janeiro: Revan, 1992.

LAGO, P. F. A consciência ecológica: a luta pelo futuro. Florianópolis, SC: Ed. da UFSC, 1991.

ODUM, E. P. Ecologia. Trad. Kurt G. Hell. São Paulo: Pioneira, 1977.

TOZONI-REIS, M. de C. Educação ambiental: natureza, razão e história. Campinas, SP: Atores Associados, 2004.

TUAN, Yi-fu. Espaço e lugar: a perspectiva da experiência. Trad. Lívia de Oliveira. São Paulo: DIFEL, 1983.

TUAN, Yi-fu. Topofilia: um estudo da percepção, atitudes e valores do meio ambiente. Trad. Lívia de Oliveira. São Paulo: DIFEL, 1980.

VERNIER, J. O meio ambiente. Trad. Marina Appenzeller. Campinas, SP: Papirus, 2004.

VINCENT, A. Ideologias políticas modernas. Trad. Ana Luísa Borges. Rio de Janeiro: Jorge Zahar, 1995.

\section{Correspondência:}

Cinthia Raquel Pergentino de Oliveira - Rua Santa Catarina, 7034 Lot.Port III, Marchal Cândido Rondon-PR

E-mail: cinthiarpo@gmail.com

Recebido em 30 de agosto de 2011

Revisado pelo autor em 05 de janeiro de 2012

Aceito em 14 de fevereiro de 2012 